\title{
A 'Missed’ Diagnosed Case of Christ-Siemens-Touraine Syndrome
}

\author{
Narayan $\mathbf{S}^{1}$
}

\begin{abstract}
Christ-Siemens-Touraine syndrome also known as Anhidrotic ectodermal dysplasia, is a rare genetic disorder, occurring in 1-100,000 live male births. A two year old male child with classical signs and symptoms of the disease, affecting skin, hairs, nails and teeth, misdiagnosed initially as a case of seborrhic dermatitis, and later as tuberculosis, is described here. Treatment includes counselling the family, skin care, avoiding high ambient temperature, and prosthodontic measures. Diagnosis as early as possible, based mainly on clinical features can prevent mortality due to hyperpyrexia and respiratory infections. Beyond early childhood, life expectancy is normal to slightly reduced.
\end{abstract}

\section{Introduction}

Ectodermal dysplasias (EDs) are a heterogeneous group of disorders characterized by developmental dystrophies of ectodermal structures, such as skin, hair, nails and teeth. Till date about 160 clinically and genetically distinct types of EDs have been described ${ }^{1}$. Collectively, its prevalence is stated as seven cases per 10,000 births $^{2}$.

Anhidrotic Ectodermal Dysplasia, also known as Christ-SiemensTouraine syndrome, is a rare genetic disorder, transmitted mostly as $X$ linked recessive form. It is the most common type of EDs ${ }^{3}$. It was first described by Thurnam in 1848 and later in the 19th century by Darwin $^{4}$. An autosomal recessive form has also been decribed ${ }^{5}$. The incidence of $X$ linked recessive form is estimated at 1-10 in 100,000 live male births, and the carrier incidence is around 17.3 in 100,000 women ${ }^{3}$. It manifests as a triad of hypohidrosis or complete absence of sweat glands, hypotrichosis and anomalous dentition.

A two year old male child with classical signs and symptoms of the disease, but still misdiagnosed due to lack of awareness among clinicians, is being reported here.

\section{The Case}

Two year old male child, product of non-consanguineous marriage, presented to us in OPD with complaints of intermittent episodes of high fever, never recorded, developing on sun exposure and relieved on keeping the child indoor. Father gave definite history of lack of sweating since birth. Baby was born as full term, appropriate for gestational age, with plastic wrap appearance of skin at birth. First
${ }^{1}$ Dr. Shambhavi Narayan, MBBS, MD, Senior Resident, Department of Paediatrics, Sawai Man Singh Medical College, Jaipur, India

\section{Address for correspondence \\ Dr. Shambhavi Narayan \\ E-mail:21me.shambhavi@gmail.com}

\section{How to cite}

Narayan S. A 'Missed' Diagnosed Case of Christ-Siemens-Touraine Syndrome. J Nepal Paediatr Soc 2017;37(1):83-85.

doi: http://dx.doi.org/10.3126/jnps.v37i1.16247

This work is licensed under a Creative Commons Attribution 3.0 License. 
six months of life were uneventful, then parents noticed cracking and peeling of skin; child was then diagnosed as having seborrheic dermatitis and given topical medications. At 10 month of age, child was again shown to a doctor for fever, poor growth and pale appearance of skin. At that time, child was prescribed anti tubercular treatment which he took for six months. Milestones were appropriately achieved. As there was no improvement child was referred to our hospital. History of poor dentation was given. There was no similar family history. On examination we found pallor, sparse and blonde scalp hairs and eyebrows, low set ears, frontal bossing, thick everted lips, peg shaped upper two incisors, absent other teeth. Skin showed cracking, nails were small and dysplastic. Child weighed $8.6 \mathrm{Kg}$ (<-3 SD according to WHO charts), Height was $79 \mathrm{~cm}$ (between -2 to -3 SD), Head circumference was $45.5 \mathrm{~cm}$. Systemic examination was normal. Blood investigation showed microcytic hypochromic anaemia $(\mathrm{Hb}=9 \mathrm{gm} / \mathrm{dl})$. Renal and liver function tests were normal. Dermatologist's opinion was taken who suggested coconut oil application and counselling of patient. Skin biopsy was done which showed thin and flattened epidermis with rudimentary sweat glands. Parents were counselled about the nature of the disease and avoidance of high ambient temperature. They were not ready for prosthodontic intervention, as suggested by dentists due to financial issues. Child was discharged after building up nutritional status.

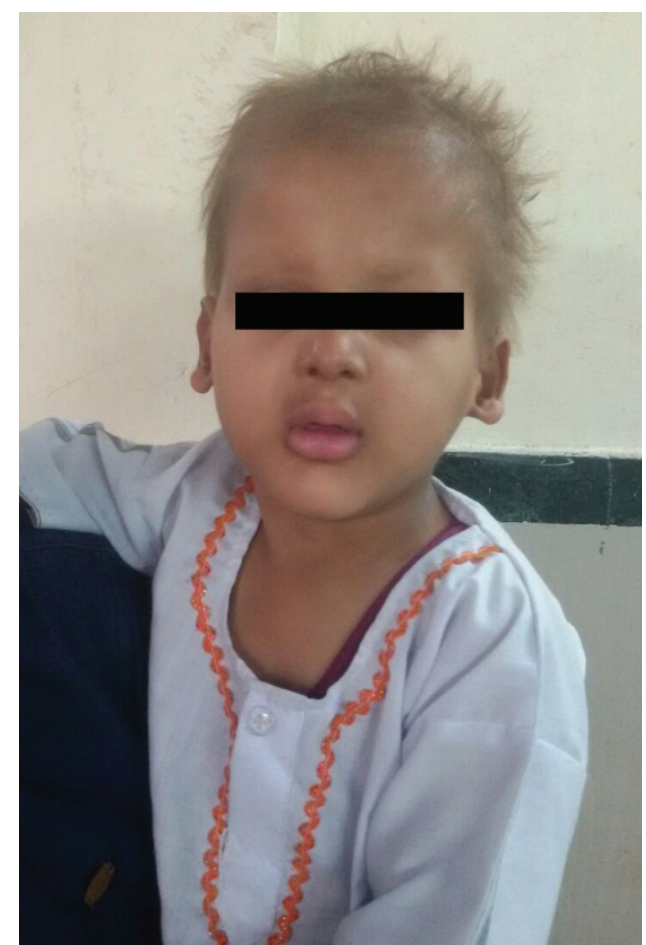

Fig 1: Showing sparse and blonde scalp hairs and eyebrows, low set ears, frontal bossing, \& thick everted lips

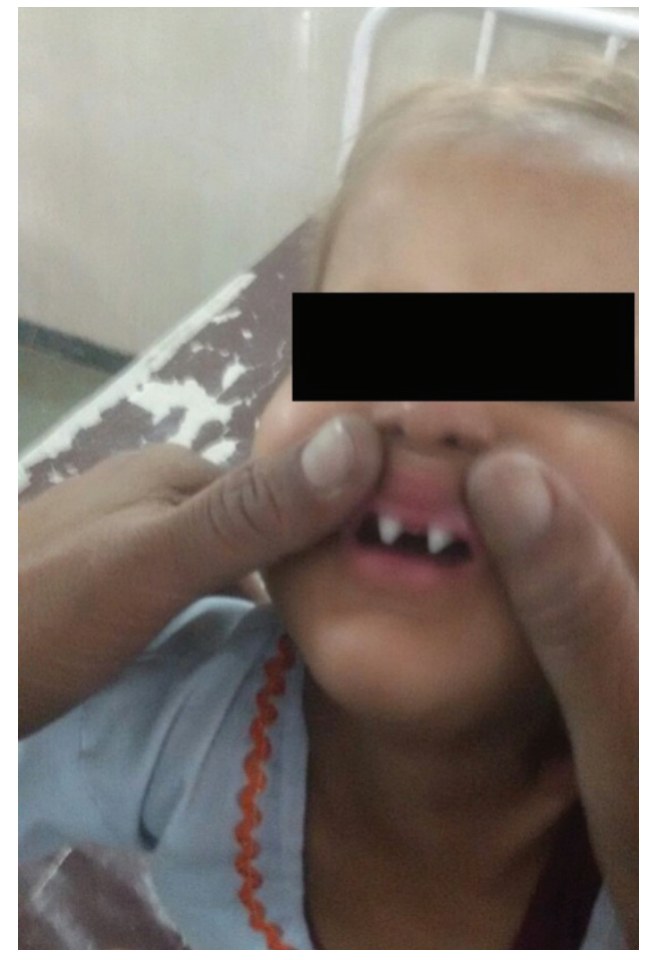

Fig 2: Shows peg shaped upper two incisors

\section{Discussion}

Ectodermal dysplasia term was coined by Weech in $1929^{2}$. X linked recessive anhidrotic/ hypohydrotic ectodermal dysplasia is its most common type $(80 \%)^{3}$. Its typical phenotypic features include soft, thin, dry skin, hyperkeratotic palms and sole, thin sparse, light colored hairs, lack of sweating, oligodontia, conical shaped teeth, wide midline diastema, frontal bossing, depressed nasal bridge, prominent supraorbital ridges, prominent and obliquely set ears, depressed midface, protuberant lips, dysplastic nails, and absent sweating. Growth failure is also common ${ }^{2}$. Delay in dentition provides an early opportunity to diagnose the condition. The upper normal limit for the first tooth to appear is 15 months $^{6}$. Carrier females do not show the complete syndrome ${ }^{4}$. Dental examination and sweat testing can help in identifying carrier females ${ }^{3}$. Genetic analysis, though not available everywhere can be used for identification of carrier females ${ }^{7}$. After initial few years, there is a general improvement in health status; but the quality of life later is badly affected by poor dentition and facial features ${ }^{3}$. Prosthodontic measures are indicated as early in life as possible, preferably before five years of life; which leads to better self-image, mastication and linguistic development ${ }^{8}$. Mortality rate as high as 30\% has been reported in literature during first two years due to respiratory infections and hyperpyrexia ${ }^{2,9}$. Beyond early childhood, the life span of a patient with one of the common types of ectodermal dysplasia is normal to slightly reduced ${ }^{2,3}$. 


\section{Conclusion}

CST syndrome, though rare can be diagnosed on the basis of clinical features. As clinicians we should be aware of the condition so that mortality can be prevented due to hyperpyrexia and respiratory infections.

\section{References}

1. Pinheiro M, Freire-Maia N. Ectodermal dysplasias: a clinical classification and a causal review. Am J Med Genet 1994;53(2):153-62. doi: https://doi.org/10.1002/ ajmg. 1320530207

2. Shah KN, Mckinster CD. Ectodermal Dysplasia. http://emedicine.medscape.com/article/1110595overview\#showall. Accessed 24/06/2015.

3. Mortier K, Wackens G. Ectodermal Dysplasia anhidrotic. Orphanet Encyclopedia. www.orpha.net/ data/patho/GB/uk- ectodermal-dysplasia-anhidrotic. pdf. Accessed 24/06/2015.

4. Ali G, Kumar M, Verma R, Khajuria V, Wadhwa MB. Anhidrotic ectodermal dysplasia (christ - seimens touraine syndrome) - case report with a review. Indian J Med Sci2000;54:541-4. PMID: 11354819

5. Gorlin RJ, Old T, Anderson VE. Hypohidrotic ectodermal dysplasla in females. A critical analysis and argument

for genetic heterogenity. Z Kinderheilkd 1970;108(1):111. PMID: 5440468

6. Pirinen S. In: Meurman, Murtomaa, LeBell, Autti, Luukkanen (eds): Therapia Odontologica. Academica Kustannus Oy, Helsinki. 1996 p. 414.

7. Zonana J, Jones $M$, Browne D, Litt M, Kramer $P$, Becker HW, Brockdorff Net al. High resolution mapping of the X-linked hypohidrotic ectodermal dysplasia (EDA) locus. Am J Hum Genet 1992;51(5):1036-46. PMCID: PMC1682855

8. Suprabha BS. Hereditary ectodermal dysplasia: A case report. J Indian Soc Pedo 2002;20:1:37-40. PMID:12435032

9. Berg D, Weingold DH, Abson KG, Olsen EA. Sweating in ectodermal dysplasia syndromes. A review. Arch Dermatol 1990;126(8):1075-9. doi:10.1001/ archderm.1990.01670320099019 